\title{
Moderate chronic kidney disease and left ventricular hypertrophy after aortic valve replacement for aortic valve stenosis
}

\author{
Umberto Benedetto, MD, Giovanni Melina, MD, Emiliano Angeloni, MD, Simone Refice, MD, \\ Gianluca Scafani, MD, Antonino Roscitano, MD, Euclide Tonelli, MD, and Riccardo Sinatra, MD
}

\begin{abstract}
Objective: Left ventricular hypertrophy regression is assumed to be one of the most important goals after aortic valve replacement for aortic stenosis. A moderate decrease in the glomerular filtration rate is associated with a significantly increased risk of left ventricular hypertrophy in hypertensive patients. The effect of moderate kidney disease on left ventricular hypertrophic remodeling in other conditions of chronic left ventricular pressure overload, such as aortic stenosis, remains unknown. Therefore we tested the hypothesis that moderate chronic kidney disease affects left ventricular mass regression in patients undergoing isolated aortic valve replacement for aortic stenosis.
\end{abstract}

Methods: In 157 patients with aortic stenosis, left ventricular mass regression was assessed at 18 months after aortic valve replacement. Among them, $73(46 \%)$ had a moderate chronic kidney disease (glomerular filtration rate between 60 and $30 \mathrm{~mL} / \mathrm{min}$ per $1.73 \mathrm{~m}^{2}$ ). Patients with severely impaired kidney function (glomerular filtration rate of $<30 \mathrm{~mL} / \mathrm{min}$ per $1.73 \mathrm{~m}^{2}$ ) were excluded.

Results: After surgical intervention, left ventricular mass was significantly lower from baseline value in both groups, but patients with moderate chronic kidney disease continued to show an increased left ventricular mass $\left(61 \pm 18\right.$ vs $\left.50 \pm 16 \mathrm{~g} / \mathrm{m}^{2.7}, P=.0001\right)$. The baseline glomerular filtration rate was significantly related to left ventricular mass at 18 months after surgical intervention $\left(\beta=-0.17, r^{2}=0.45, P=.01\right)$ and left ventricular mass absolute $\left(\beta=0.18, r^{2}=0.19, P=.03\right)$ and relative $\left(\beta=0.20, r^{2}=0.21, P=.02\right)$ regression. These associations persisted after adjusting for confounding factors, including hypertension and patient-prosthesis mismatch. After a mean time of $34 \pm 12$ months from surgical intervention, congestive heart failure symptoms developed mainly in subjects with moderate chronic kidney disease (adjusted hazard ratio, 1.9; 95\% confidence interval, $1.2-3.9 ; P=.035)$.

Conclusions: Patients with aortic stenosis with concomitant moderate chronic kidney disease present a less evident left ventricular mass regression after aortic valve replacement. Moreover, this condition is related to an increased occurrence of congestive heart failure after surgical intervention. (J Thorac Cardiovasc Surg 2010;139:881-6)

Left ventricular (LV) hypertrophy usually occurs in patients with aortic valve stenosis as a consequence of chronic pressure overload. LV mass regression is assumed to be one of the most important goals after aortic valve replacement (AVR) because residual LV hypertrophy is associated with an increased rate of adverse events, such as myocardial infarction, sudden or arrhythmic death, and congestive heart failure. ${ }^{1}$ However, a large number of patients continue to show some degree of LV hypertrophy after surgical intervention. Factors affecting normalization of LV mass are not completely understood and include uncontrolled hypertension $^{2}$ and patient-prosthesis mismatch (PPM). ${ }^{1,3}$

\footnotetext{
From the Cardiac Surgery Department, University of Rome La Sapienza, Policlinico S. Andrea, Rome, Italy.

Disclosures: None.

Received for publication Jan 21, 2009; revisions received April 14, 2009; accepted for publication May 22, 2009.

Address for reprints: Umberto Benedetto, MD, Cardiac Surgery Department, II School of Medicine, University of Rome “La Sapienza," Via di Grottarossa 1039, Rome, Italy (E-mail: u2benedetto@libero.it).

0022-5223/\$36.00

Copyright (C) 2010 by The American Association for Thoracic Surgery

doi:10.1016/j.jtcvs.2009.05.041
}

However, these associations are not always consistent, ${ }^{4,5}$ suggesting that such aspects cannot fully explain residual LV hypertrophy.

LV hypertrophy severity has been shown to be strongly related to renal function in hypertensive patients. ${ }^{6}$ An independent relationship between indicators of renal function and LV mass is present even in subjects with apparently normal renal function. It is well established in patients with chronic kidney disease (CKD) that there is a continuous inverse relationship between LV mass and glomerular filtration rate (GFR), regardless of hemodynamic overload. In this respect sodium retention and the attendant/associated alteration in the renin-angiotensin-aldosterone system (RAAS) and sympathetic overactivity are important causative mechanism of LV hypertrophy. ${ }^{7}$

Nowadays, patients coming to AVR for aortic stenosis are more frequently older and more likely to present with some degree of kidney dysfunction. Detailed analysis of the association between renal function and LV mass in patients with aortic stenosis undergoing AVR might provide useful information to redefine risk stratification and generate hypotheses 


$\begin{aligned} & \text { Abbreviations and Acronyms } \\ & \text { ACEI/ARB }= \text { angiotensin-converting } \\ & \text { enzyme inhibitors/angiotensin } \\ & \text { receptor blockers } \\ & \text { AVR } \quad= \text { aortic valve replacement } \\ & \text { CKD }=\text { chronic kidney disease } \\ & \text { EOA }=\text { effective orifice area } \\ & \text { GFR }=\text { glomerular filtration rate } \\ & \text { LV }=\text { left ventricular } \\ & \text { PPM }=\text { patient-prosthesis mismatch } \\ & \text { RAAS }=\text { renin-angiotensin-aldosterone } \\ & \text { system }\end{aligned}$

to better understand factors influencing LV hypertrophy regression after surgical intervention. Therefore we tested the hypothesis that a moderate decrease in kidney function affects LV mass regression in hospital survivors undergoing AVR for aortic stenosis.

\section{MATERIALS AND METHODS}

We prospectively evaluated consecutive hospital survivors who underwent isolated AVR for aortic valve stenosis (peak velocity, $>3.5 \mathrm{~m} / \mathrm{s}$ ) in one institution between May 2004 and July 2007. One hundred ninetyfour patients were screened. Exclusion criteria were concomitant native aortic valve regurgitation more than moderate, concomitant coronary artery disease, previous cardiac surgery, and previous renal transplantation. A creatinine-based equation for estimating the GFR was used to identify patients with baseline impaired kidney function. For this purpose, the 4-variable Modification of Diet in Renal Disease equation was used, as follows:

$$
\begin{aligned}
G F R= & 186 \times\left(S_{C r}\right)-1.154 \times(\text { Age })-0.203 \times(0.742 \text { if female }) \\
& \times(1.212 \text { if black }) .
\end{aligned}
$$

Scr is serum creatinine value expressed in milligrams per deciliter. ${ }^{8}$ According to the current Kidney Disease Outcomes Quality Initiative guidelines, moderate CKD was defined as a GFR between 60 and $30 \mathrm{~mL} / \mathrm{min}$ per $1.73 \mathrm{~m}^{2}$, severely impaired kidney function was defined as a GRF between 30 and $15 \mathrm{~mL} / \mathrm{min}$ per $1.73 \mathrm{~m}^{2}$, and established renal failure was defined as a GFR of less than $15 \mathrm{~mL} / \mathrm{min}$ per $1.73 \mathrm{~m}^{2} .{ }^{8}$ Because of the small number of patients with baseline severely impaired kidney function $(\mathrm{n}=10)$ and established renal failure $(n=2)$, they were not included.

Finally, the study population consisted of 157 patients. One hundred forty of 157 received a bioprosthesis (Carpentier-Edwards Perimount Magna; Edwards Lifesciences LLC, Irvine, Calif); others had a mechanical prosthesis (Carbomedics Standard Aortic Valve, Carbomedics Inc, Austin, Tex, or St Jude Medical Mechanical Heart Valve Hemodynamic Plus Series, St Jude Medical, St Paul, Minn). After surgical intervention, all patients were periodically reviewed. At each follow-up visit, blood pressure was measured 3 times in the left arm after the subjects had been at rest in the sitting position for 5 minutes or longer, and the mean value of the 3 separate systolic blood pressure and 3 separate diastolic blood pressure measurements was used to determine the reported blood pressure in accordance with the recent European Society of Hypertension and the European Society of Cardiology Guidelines. ${ }^{9}$ Hypertensive therapy was instituted and eventually implemented to achieve a systemic blood pressure of less than 140/90 $\mathrm{mm} \mathrm{Hg}$. Uncontrolled hypertension was defined as systolic blood pressure of $140 \mathrm{~mm} \mathrm{Hg}$ or greater or diastolic blood pressure of $90 \mathrm{~mm} \mathrm{Hg}$ or greater, regardless of receiving antihypertensive medication. ${ }^{9}$ LV mass regression was assessed by performing echocardiographic analysis preoperatively and at 18 months after surgical intervention according to previous studies showing a highly significant LV mass reduction during the first 18 months after AVR and no further change in LV mass between 1.5 and 10 years. ${ }^{4}$ Thereafter, adverse events were ascertained by means of telephone interviews and hospital records.

Sudden death was defined as unexpected and otherwise unexplained death within 1 hour from the onset of witnessed terminal symptoms or unexplained death during sleep. Arrhythmic death was defined as death from a cardiac rhythm disturbance requiring external defibrillation or pacing or documented hemodynamically unstable cardiac arrhythmia. Congestive heart failure was defined according to the Framingham clinical diagnostic criteria. $^{10}$

LV mass was calculated according to the European and American Associations of Echocardiography guidelines ${ }^{11}$ and normalized by height $t^{2.7} \cdot{ }^{12}$ LV hypertrophy was defined as an LV mass index of $50 \mathrm{~g} / \mathrm{m}^{2.7}$ or greater in men and $47 \mathrm{~g} / \mathrm{m}^{2.7}$ or greater in woman. ${ }^{13} \mathrm{LV}$ volumes were estimated by using the $\mathrm{z}$-derived method, ${ }^{14}$ and ejection fraction was calculated as follows:

\section{(End-diastolic volume-End-systolic volume)/End-diastolic volume.}

The prosthesis valve effective orifice area (EOA) was derived from the continuity equation: $\left(L V O T^{2} \times 0.785 \times T V I_{1}\right) / T V I_{2}$, where $L V O T$ is the diameter of the $\mathrm{LV}$ outflow tract and $T V I_{1}$ and $T V I_{2}$ are the time-velocity integrals at the LV outflow tract and across the aortic valve, respectively. The mean gradient was measured by means of continuous-wave Doppler echocardiographic analysis and the simplified Bernoulli equation. PPM was defined as an EOA indexed for body surface area of $0.85 \mathrm{~cm}^{2} / \mathrm{m}^{2}$ or less. ${ }^{3}$ All Doppler measurements were obtained as the average of at least 3 cycles in patients with sinus rhythm or more than 5 cycles in those with atrial fibrillation.

Differences in baseline characteristics stratified by moderate CKD were compared by using the $\chi^{2}$ test for categorical variables and the $t$ test for continuous variables (log-transformed when required). LV mass regression was assessed in terms of indexed LV mass at 18 months after surgical intervention, absolute LV mass regression (baseline indexed LV mass minus indexed LV mass at 18 months after surgical intervention), and relative LV mass regression (absolute LV mass regression/baseline indexed LV mass). Pearson's correlation coefficient was used to evaluate the correlation between LV mass regression and individual estimated GFR. A multivariate linear regression was performed to assess the independent value of GFR on LV mass regression, adjusting for clinical variables selected on the basis of face validity that were associated with GFR at a $P$ value of less than .05 .

Cumulative event-free survival was measured by using the KaplanMaier method, and unadjusted differences were compared with the log-rank test. Cox proportional hazards regression was used to assess the independent effect of moderate CKD on the outcome of interest, adjusting for clinical variables associated at a $P$ value of less than .1. Before inclusion, these were assessed for association (if showing parallel regression lines [ie, colinearity]) and tested by using a stepwise forward selective procedure. If 2 or more variables were associated with each other, only the variable showing the strongest relationship was included, and the others were discarded. In the multivariate linear regression analysis data were expressed as regression coefficients $(\beta)$, determination coefficients $\left(r^{2}\right)$, and $P$ values.

Statistical analysis was performed with the Statistical Package for the Social Sciences, version 11 (SPSS, Inc, Chicago, Ill). The authors had full access to the data and take responsibility for their integrity. All authors have read and agreed to the report as written.

\section{RESULTS}

Baseline mean GFR was $62 \pm 21 \mathrm{~mL} / \mathrm{min}$ per $1.73 \mathrm{~m}^{2}$. According to the definition given in the Methods section, moderate CKD was present in $73(46 \%)$ of 157 patients. 
Subjects with moderate CKD were older and more likely to be female. Baseline indexed LV mass and LV hypertrophy occurrence were significantly increased in patients with moderate CKD. Estimated GFR was inversely related to baseline indexed LV mass $\left(\beta=-0.24, r^{2}=0.32, P=\right.$ $.001)$. Native aortic valve stenosis severity and baseline $\mathrm{LV}$ ejection fraction did not differ between the 2 groups. Implanted prosthesis size and type were similar in the 2 groups (Table 1).

At 18 months after surgical intervention, indexed LV mass was significantly less than the baseline value in both groups, but patients with moderate CKD continued to show an increased indexed LV mass when compared with patients with preserved kidney function. Consequently, the continued prevalence of LV hypertrophy remained higher in the moderate CKD group. No relevant differences were found in mean prosthesis indexed EOA and PPM occurrence (Table 1). Of note, despite medical therapy, uncontrolled hypertension occurred, with no differences between the 2 groups. Patients with CDK were also more likely to use $\beta$ blockers, but no differences existed for angiotensin-converting enzyme inhibitors/angiotensin receptor blockers (ACEI/ ARB) use. Mean GFR did not significantly differ from preoperative values. Baseline estimated GFR was significantly related to $\mathrm{LV}$ mass $/ \mathrm{m}^{2.7}$ at 18 months after surgical intervention (Figure 1) and LV mass $/ \mathrm{m}^{2.7}$ absolute and relative regression, and these associations persisted after adjusting for baseline LV mass $/ \mathrm{m}^{2.7}$, female sex, uncontrolled hypertension, PPM, and ACEI/ARB use (Table 2).

Clinical follow-up was completed for all patients after a mean of $34 \pm 12$ months. During the study period, 6 patients died ( 3 in each group). There were 2 sudden deaths, 1 arrhythmic death, 1 end-stage congestive heart failure death, 1 fatal stroke, and 1 pneumonia-related death. Nonfatal acute myocardial infarction occurred in 2 cases (both in the moderate CKD group). Kaplan-Meier analysis showed a decreased

TABLE 1. Baseline, operative, and 18-month follow-up data stratified for moderate CKD occurrence

\begin{tabular}{|c|c|c|c|}
\hline & No CKD $(n=84)$ & Moderate CKD $(n=73)$ & $P$ value \\
\hline \multicolumn{4}{|l|}{ Baseline data } \\
\hline Mean age (y) & $68 \pm 11$ & $73 \pm 8$ & .0007 \\
\hline Female sex $(\%)$ & 34 & 50 & .06 \\
\hline Baseline hypertension $(\%)$ & 45 & 59 & .11 \\
\hline Diabetes $(\%)$ & 25.0 & 26.0 & .967 \\
\hline Congestive heart failure $(\%)$ & 43 & 52 & .33 \\
\hline Mean GFR $\left(\mathrm{mL} / \mathrm{min}\right.$ per $\left.1.73 \mathrm{~m}^{2}\right)$ & $78 \pm 13$ & $45 \pm 12$ & $<.0001$ \\
\hline Atrial fibrillation $(\%)$ & 15.5 & 13.7 & .92 \\
\hline Mean transvalvular peak gradient $(\mathrm{mm} \mathrm{Hg})$ & $80 \pm 26$ & $81 \pm 29$ & .75 \\
\hline Mean aortic valve area $\left(\mathrm{cm}^{2}\right)$ & $0.75 \pm 0.1$ & $0.73 \pm 0.1$ & .21 \\
\hline Mean LV ejection fraction (\%) & $64 \pm 10$ & $65 \pm 8$ & .60 \\
\hline Mean LV mass index $\left(\mathrm{g} / \mathrm{m}^{2.7}\right)$ & $63 \pm 19$ & $71 \pm 18$ & .01 \\
\hline LV hypertrophy $(\%)$ & 69.6 & 90.2 & .003 \\
\hline \multicolumn{4}{|l|}{ Operative data } \\
\hline Bioprosthesis (\%) & 87 & 92 & .3 \\
\hline Mean prosthesis size $(\mathrm{mm})$ & $21.09 \pm 1.86$ & $20.75 \pm 1.94$ & .26 \\
\hline Mean aortic crossclamp time (min) & $85 \pm 20$ & $91 \pm 23$ & .08 \\
\hline Mean cardiopulmonary bypass time (min) & $101 \pm 31$ & $111 \pm 41$ & .08 \\
\hline \multicolumn{4}{|l|}{ 18-mo Follow-up data } \\
\hline Uncontrolled hypertension $(\%)$ & 27.8 & 30.1 & .88 \\
\hline \multicolumn{4}{|l|}{ Medication use } \\
\hline ACEI $(\%)$ & 50 & 53.4 & .79 \\
\hline $\mathrm{ARB}(\%)$ & 9.5 & 16.4 & .29 \\
\hline$\beta$-blockers (\%) & 23.8 & 41.1 & .03 \\
\hline Mean GFR $\left(\mathrm{mL} / \mathrm{min}\right.$ per $\left.1.73^{\mathrm{m} 2}\right)$ & $80 \pm 12^{*}$ & $46 \pm 12 \dagger$ & $<.0001$ \\
\hline Mean LV ejection fraction (\%) & $68 \pm 12$ & $66 \pm 1$ & .22 \\
\hline Mean LV mass index $\left(\mathrm{g} / \mathrm{m}^{2.7}\right)$ & $50 \pm 26 \ddagger$ & $61 \pm 25 \S$ & .0001 \\
\hline LV hypertrophy $(\%)$ & 35.0 & 58.6 & .006 \\
\hline Mean transprosthesis peak gradient $(\mathrm{mm} \mathrm{Hg})$ & $19 \pm 11$ & $20 \pm 11$ & .57 \\
\hline Mean prosthesis EOA $\left(\mathrm{cm}^{2}\right)$ & $1.35 \pm 0.33$ & $1.27 \pm 0.39$ & .16 \\
\hline Mean indexed EOA $\left(\mathrm{cm}^{2} / \mathrm{m}^{2}\right)$ & $0.87 \pm 0.18$ & $0.84 \pm 0.2$ & .32 \\
\hline $\mathrm{PPM}(\%)$ & 36.6 & 40.1 & .77 \\
\hline
\end{tabular}

$C K D$, Chronic kidney disease; $G F R$, glomerular filtration rate; $L V$, left ventricular; $A C E I$, angiotensin-converting enzyme inhibitor; $A R B$, angiotensin receptor blockers; $E O A$, effective orifice area; $P P M$, patient-prosthesis mismatch. $* P=.33$ when compared with baseline values (paired $t$ test). $\dagger P=.59$ when compared with baseline values (paired $t$ test). $\ddagger P=.0003$ when compared with baseline values (paired $t$ test). $\S P=.006$ when compared with baseline values (paired $t$ test). 


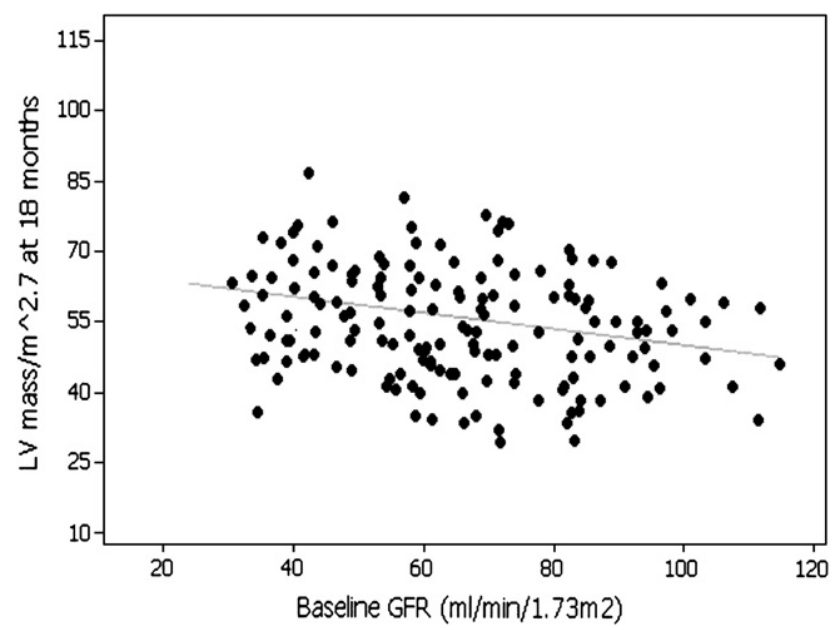

FIGURE 1. The relationship between indexed left ventricular $(L V)$ mass at 18 months after surgical intervention and baseline glomerular filtration rate $(G F R)$ is presented graphically (regression equation: $\mathrm{y}=67.5-0.172 \mathrm{x}$ ).

congestive heart failure-free survival in patients with moderate CKD (unadjusted hazard ratio, $2.3 ; 95 \%$ confidence interval, $1.3-3.5 ; P=.03$; Figure 2). After adjusting for preoperative congestive heart failure, LV ejection fraction, baseline LV mass $/ \mathrm{m}^{2.7}$, PPM, uncontrolled hypertension, and ACEI/ARB use, moderate CKD disease remained an independent predictor of congestive heart failure (adjusted hazard ratio, $1.9 ; 95 \%$ confidence interval, $1.2-3.9 ; P=.035)$.

\section{DISCUSSION}

The principal result of this observational study was that patients with aortic stenosis with concomitant moderately impaired kidney function presented with a higher baseline LV mass and less evident LV hypertrophy regression after AVR. These associations were independent from the occurrence of uncontrolled hypertension and PPM.

Post-AVR residual hypertrophy is a complex phenomenon, and it still represents a vexing problem that has an effect on morbidity and mortality. There is no doubt that hemodynamic factors, such as uncontrolled blood pressure, have an important effect on residual LV hypertrophy, but other fac- tors regulating the growth of LV mass might influence the post-AVR remodeling process.

\section{Moderate CKD and LV Hypertrophy}

LV hypertrophy is frequently observed in patients with end-stage renal failure and is an independent predictor of cardiovascular mortality and heart failure. ${ }^{15}$ Recent studies have shown that even a moderate decrease in GFR is associated with a significantly increased risk of LV hypertrophy, regardless of blood pressure control and other traditional risk factors. ${ }^{6}$ That estimated GFR is an independent determinant of LV mass indicates that decreased kidney function per se contributes to LV hypertrophy. This association has been observed in a cohort of unselected middle-aged patients with hypertension, ${ }^{6}$ and no previous study investigated the effect of moderate CKD on LV hypertrophic remodeling in other conditions of chronic LV pressure overload, such as aortic stenosis.

Aortic stenosis is rapidly becoming a typical disease of aging, with an increasing number of patients presenting with some degrees of concomitant kidney dysfunction. In the present study we were able to demonstrate that moderate reduction of kidney function is a frequent event in patients undergoing AVR for aortic stenosis; these patients had an increased preoperative LV mass and showed a reduced LV mass regression after surgical intervention. In addition, subjects with moderate CKD had an increased risk of congestive heart failure symptoms after surgical intervention, and this might be partially explained by their increased LV mass. ${ }^{15}$

The lack of LV hypertrophy regression after AVR for aortic stenosis has been long considered a pure consequence of hemodynamic overload because of uncontrolled hyperten$\operatorname{sion}^{2}$ or PPM. ${ }^{3}$ However, some studies have suggested that pressure overload per se did not completely account for the increased LV mass, ${ }^{4,5}$ and the extent of its regression after the removal of the hemodynamic trigger seems to be influenced by the presence of presumably irreversible myocyte abnormalities occurring in the context of marked hypertrophic processes. ${ }^{1,4,5}$ As shown in hypertensive patients, moderate impaired kidney function exacerbates the hypertrophic adaptive process to pressure overload. ${ }^{6}$ In the presence of

TABLE 2. Correlations between baseline glomerular filtration rate expressed as milliliters per minute per $1.73 \mathrm{~m}^{2}$ and indexes of LV mass regression

\begin{tabular}{lccc}
\hline \multicolumn{1}{c}{ Model } & Indexed LV mass at 18 mo & LV mass absolute regression & LV mass relative regression \\
\hline Unadjusted & $\beta=-0.17$ & $\beta=0.18$ & $\beta=0.20$ \\
& $r^{2}=0.45$ & $r^{2}=0.19$ & $r^{2}=0.21$ \\
& $P=.01$ & $P=.03$ & $P=.02$ \\
Adjusted for Female sex & $\beta=-0.12$ & $\beta=0.21$ & $\beta=0.22$ \\
Baseline indexed LV mass & $r^{2}=0.31$ & $r^{2}=0.23$ & $r^{2}=0.20$ \\
Uncontrolled hypertension & $P=.03$ & $P=.02$ & $P=.01$ \\
PPM & & & \\
ACEI/ARB use & & &
\end{tabular}

$L V$, Left ventricular; $P P M$, patient-prosthesis mismatch; $A C E I$, angiotensin-converting enzyme inhibitor; $A R B$, angiotensin receptor blockers. 


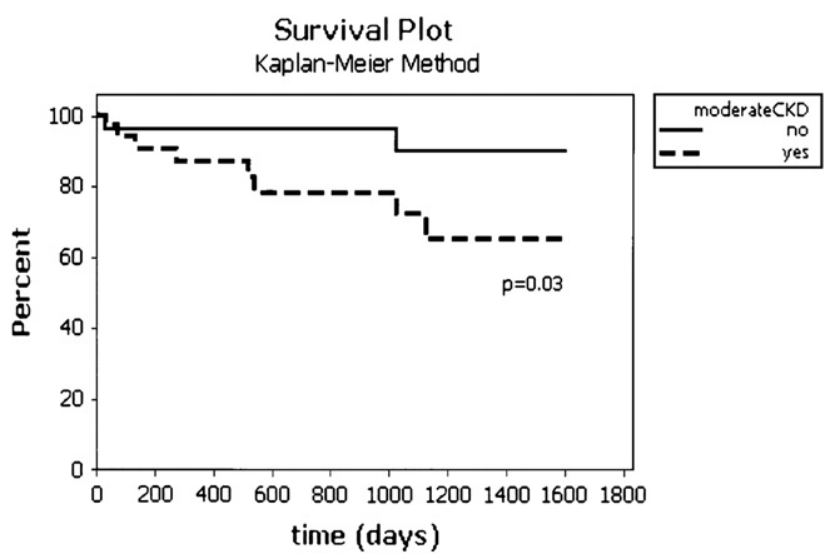

FIGURE 2. Congestive heart failure-free survival according to the presence of baseline moderate chronic kidney disease (CKD; hazard ratio, 2.3; $95 \%$ confidence interval, $1.3-3.5 ; P=.03)$.

aortic stenosis, this might result in irreversible myocardial change, thus affecting LV mass regression after AVR.

Aortic stenosis-related LV hypertrophy in patients with moderate CKD can be enhanced by several mechanisms involving sodium retention and neurohumoral factors, such as activation of the RAAS. ${ }^{16}$ There is increasing evidence to suggest that angiotensin II might directly contribute to the development of LV hypertrophy through its growth factor properties on smooth muscle cells and cardiac myocytes. ${ }^{17}$ Angiotensin II plays a role in cardiac fibrosis by stimulating transforming growth factor $\beta 1$ gene expression and induction of fibroblast proliferation and collagen deposition. ${ }^{18}$ In addition, chronic renal disease is associated with a sympathetic overactivity. It has been hypothesized that the sympathetic nervous system might interact with the RAAS $^{19}$ and contribute to the development and progression of LV hypertrophy. Finally, secondary hyperparathyroidism related to moderately impaired kidney function might contribute to the LV hypertrophic process. ${ }^{20}$ In fact, parathyroid hormone receptors have been demonstrated to induce hypertrophy of myocytes.

This study has some limitations. Although we identified the association between baseline GFR and LV mass regression, causality cannot be proved. Because of the few late deaths recorded, we cannot draw any conclusions about the effect of moderate CKD on overall or cardiac mortality after AVR. Finally, the definition of LV hypertrophy we adopted was obtained from studies in the general population, and it is poorly applied to patients with surgical aortic valve stenosis. Therefore we analyzed the relationship between kidney function and LV hypertrophy by using LV mass as a continuous variable. We used indexation by body height because it was suggested to be more appropriate for patients with $\mathrm{CKD} .^{13}$

\section{Clinical Implications}

Our results strengthen the usefulness of routinely determining GFR in patients with aortic stenosis not only to evaluate renal function but also to stratify their cardiovascular risk. These patients are suggested to be characterized by a marked hypertrophic myocardial response to the increased afterload and delayed LV reverse remodeling after AVR.

For these patients, the opportunity of an earlier operation to prevent the irreversible myocardial changes related to marked LV hypertrophic process and to reduce the risk of residual LV hypertrophy should be investigated. In addition, the importance of the RAAS in mediating cardiac hypertrophy in patients with CKD strengthens the usefulness of routine angiotensin-converting enzyme inhibitor use in this high-risk subgroup regardless of blood pressure control and suggests the potential role of type 1 angiotensin II receptor antagonists to completely inhibit the action of angiotensin II in this setting. ${ }^{9}$ Further investigations are required to confirm our findings.

\section{References}

1. Mihaljevic T, Nowicki ER, Rajeswaran J, Blackstone EH, Lagazzi L, Thomas J, et al. Survival after valve replacement for aortic stenosis: implications for decision making. J Thorac Cardiovasc Surg. 2008;135:1270-8.

2. Gaudino M, Alessandrini F, Glieca F, Luciani N, Cellini C, Pragliola C, et al. Survival after aortic valve replacement for aortic stenosis: does left ventricular mass regression have a clinical correlate? Eur Heart J. 2005;26:51-7.

3. Tasca G, Mhagna Z, Perotti S, Centurini PB, Sabatini T, Amaducci A, et al. Impact of patient-prosthesis mismatch on cardiac events and midterm mortality after aortic valve replacement in patients with pure aortic stenosis. Circulation. 2006; 113:570-6.

4. Lund O, Emmertsen K, Dørup I, Jensen FT, Flø C. Regression of left ventricular hypertrophy during 10 years after valve replacement for aortic stenosis is related to the preoperative risk profile. Eur Heart J. 2003;24:1437-46.

5. Hanayama N, Christakis GT, Mallidi HR, Rao V, Cohen G, Goldman BS, et al. Determinants of incomplete left ventricular mass regression following aortic valve replacement for aortic stenosis. J Card Surg. 2005;20:307-13.

6. Perticone F, Maio R, Ruberto C, Cassano S, Tripepi G, Perticone M, et al. Kidney function and risk factors for left ventricular hypertrophy in untreated uncomplicated essential hypertension. Am J Kidney Dis. 2008;52:74-84.

7. Wang AY, Li PK, Lui SF, Sanderson JE. Angiotensin converting enzyme inhibition for cardiac hypertrophy in patients with end-stage renal disease: what is the evidence? Nephrology. 2004;9:190-7.

8. Giles PD, Fitzmaurice DA. Formula estimation of glomerular filtration rate: have we gone wrong? BMJ. 2007;334:1198-200.

9. Mancia G, De Backer G, Dominiczak A, Cifkova R, Fagard R, Germano G. 2007 ESH-ESC practice guidelines for the management of arterial hypertension: ESHESC Task Force on the Management of Arterial Hypertension. J Hypertens. 2007; 25:1751-62.

10. McKee PA, Castelli WP, McNamara PM, Kannel WB. The natural history of congestive heart failure: the Framingham study. N Engl J Med. 1971;285:1441-6.

11. Lang RM, Bierig M, Devereux RB, Flachskampf FA, Foster E, Pellikka PA, et al Recommendations for chamber quantification. Eur J Echocardiogr. 2006;7: 79-108.

12. de Simone G, Daniels SR, Devereux RB, Meyer RA, Roman MJ, de Divitiis O et al. Left ventricular mass and body size in normotensive children and adults: assessment of allometric relations and of the impact of overweight. $J$ Am Coll Cardiol. 1992;19:1550-8.

13. Zoccali C, Benedetto FA, Mallamaci F, Tripepi G, Giacone G, Cataliotti A, et al Prognostic impact of the indexation of left ventricular mass in patients undergoing dialysis. J Am Soc Nephrol. 2001;12:2768-74.

14. de Simone G, Devereux RB, Ganau A, Hahn RT, Saba PS, Mureddu GF, et al. Estimation of left ventricular chamber and stroke volume by limited M-Mode echocardiography and validation by two-dimensional and Doppler echocardiography. Am J Cardiol. 1996;78:801-7.

15. Verdecchia P, Angeli F, Achilli P, Castellani C, Broccatelli A, Gattobigio R, et al. Echocardiographic left ventricular hypertrophy in hypertension: marker for future events or mediator of events? Curr Opin Cardiol. 2007;22:329-34. 
16. Dahlof B. Effect of angiotensin II blockade on cardiac hypertrophy and remodeling: a review. J Hum Hypertens. 1995;9(suppl):S37-44.

17. Baker KM, Chernin MI, Wixson SK, Aceto JF. Renin-angiotensin system involvement in pressure-overload cardiac hypertrophy in rats. Am J Physiol Heart Circ Physiol. 1990;28:H324-32.

18. Kupfahl C, Pink D, Friedrich K, Zurbrügg HR, Neuss M, Warnecke C, et al. Angiotensin II directly increases transforming growth factor beta 1 and osteopontin and indirectly affects collagen mRNA expression in the human heart. Cardiovasc Res. 2000;46:463-75.

19. Matsukawa T, Gotoh E, Minamisawa K, Kihara M, Ueda S, Shionoiri H, et al. Effects of intravenous infusions of angiotensin II on muscle sympathetic nerve activity in humans. Am J Physiol. 1991;261:R690-6.

20. Salen FN, Schirmer H, Sundsfjord J, Jorde R. Parathyroid hormone and left ventricular hypertrophy. Eur Heart J. 2003;24:2054-60.

Access to The Journal of Thoracic and Cardiovascular Surgery Online is reserved for print subscribers!

Full-text access to The Journal of Thoracic and Cardiovascular Surgery Online is available for all print subscribers. To activate your individual online subscription, please visit The Journal of Thoracic and Cardiovascular Surgery Online, point your browser to http://www.mosby.com/jtcvs, follow the prompts to activate your online access, and follow the instructions. To activate your account, you will need your subscriber account number, which you can find on your mailing label (note: the number of digits in your subscriber account number varies from 6 to 10). See the example below in which the subscriber account number has been circled:

\section{Sample mailing label}

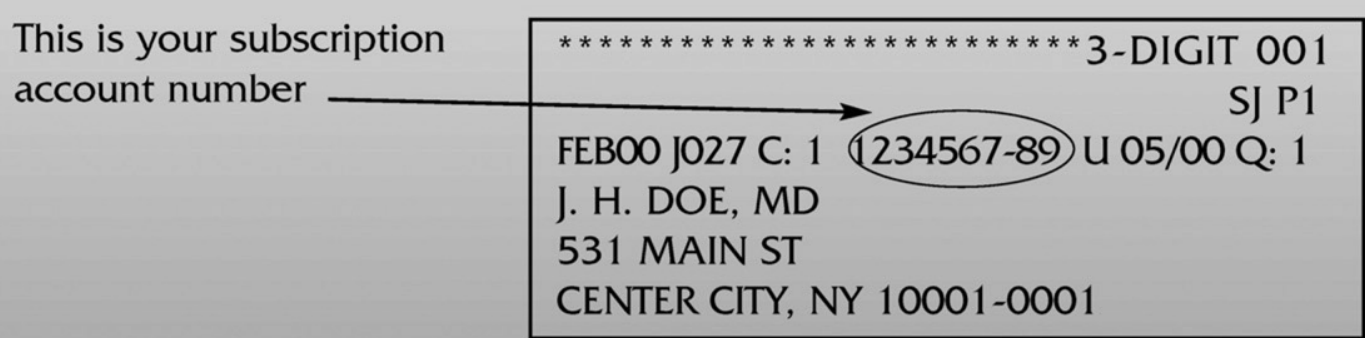

Personal subscriptions to The Journal of Thoracic and Cardiovascular Surgery Online are for individual use only and may not be transferred. Use of The Journal of Thoracic and Cardiovascular Surgery Online is subject to agreement to the terms and conditions as indicated online. 